\title{
Research on the Reform of Advertising Design Teaching in New Media Era
}

\author{
Yi Chen \\ Zhuhai College of Jilin University, Zhuhai Guangdong 519041 China
}

Keywords: new media; advertising design; teaching reform

\begin{abstract}
Advertising is an important way to convey business information. In the new media era, the communication mode of advertisement has changed a lot. In this context, traditional advertising design teaching has some defects, which affects the effect of advertising teaching. Therefore, advertising teaching should be combined with the development of the times for necessary reform. The teaching content should focus on improving the quality and skills of students under the condition of new media. The reform of advertising design teaching should highlight professional features. The reform of advertising design teaching should be helpful to improve the teaching effect.
\end{abstract}

\section{Introduction}

Advertisement is an important form of commercial publicity and an effective way to convey commercial information. There is a direct relationship between the teaching effect of advertising design and advertising effect. Advertising design is different from other designs and requires creative thinking. The design content must have certain commercial value, must attract the public attention. Therefore, advertising design teaching has certain particularity. In the current new media era, the way of information communication has changed greatly. The original teaching method is difficult to adapt to the development of The Times. We can improve the overall effect of teaching by means of teaching reform. This contributes to the improvement of students' comprehensive quality.

\section{Development and Changes of Advertising in the New Media Era}

At present, due to the progress of information technology, new media has achieved rapid development. The development of new media has changed the public access to information. The change has also affected the advertising industry. The way information is disseminated in the advertising industry has also changed dramatically. The way advertising permeates the public has changed. The public's understanding of advertising content will also be influenced by new media. New media is the product of the development of network information technology. In the new media era, the content of advertisement communication can be more abundant, especially the application of current multimedia technology. Advertising has more features than new video and facial-making techniques. The content of advertisement has a new art form, and the content of advertisement will influence the thinking of the public. It can also be seen from the communication form of advertising media that the traditional advertisement USES the material object as the medium, such as using paper print for advertising publicity. In the new media era, advertisement will be transmitted in various ways, such as light wave and sound wave, especially through virtualization and digital media. Advertising has a new way of spreading. The information communication of new media is characterized by openness. This expands the scope of advertising. The advertisement USES the new media technology design facilitates the advertisement content sharing. Advertising can be decentralized. This increases the effect of transmission. Traditional advertising media has limitations. The dissemination of advertisements needs to be accomplished by means of entities. The dissemination of advertising content and content sharing will also have certain restrictions. Therefore, traditional advertising communication has the restriction of media centralization and access mechanism. Under these conditions, the influence of advertising is insufficient. In the new media era, advertising communication carriers have the characteristics of virtualization. Content distribution can radiate to a greater extent. This promoted the development of advertising industry, 
so advertising design and teaching should adapt to the characteristics of new media for teaching reform.

\section{Reform Direction of Advertising Design Teaching in New Media Era}

Advertising production includes text, image, animation and other content. In addition, it also needs to pay attention to the application of color, the attraction of content. So, design is particularly important. The content of the advertisement should be easily accepted by the audience. Advertising works should attract attention through creative design. The design content should arouse people's divergent thinking and generate associative space. Therefore, the effect of advertising design should ensure the effect of information transmission. Advertising is designed to deliver information quickly. The basic attribute of advertisement is information medium, so the transmission of information content should ensure its effectiveness. The creativity of advertisement design helps to guarantee the communication effect of advertisement content. It needs to attract the attention of the audience. Many of the city's high streets, for example, have huge billboards. The content of the billboard adopts a unique design. It's about getting attention. The effect of advertising design is reflected in that it attracts viewers' attention and raises potential consumers' attention. So, advertisement design should pay attention to increase attraction. This also reflects the essential characteristics of advertising. As advertising plays an important role in information transmission, advertising is an important way to realize the dissemination of commercial information. Therefore, advertising design teaching should highlight students' design ability and improve students' innovation ability. We should enable students to enhance the communication effect of advertisements through unique design. From the current advertising teaching effect to see that our teaching is bound by traditional thinking. Advertisement design has many problems, such as homogenization, excessive reference content and lack of creative design. These designers have struggled to adapt to the advertising demands of the media age. Therefore, advertising design teaching needs to be reformed to improve students' design ability and level.

\section{Problems in Current Advertising Design Teaching}

\subsection{Professional features to be strengthened}

Advertising design majors are closely related to reality, so the teaching content is mainly aimed at the application of design software. The ability to design software applications needs to be strengthened through hands-on practice. This is also the advertising design professional teaching focus. There are many types of design software that are used in different fields to achieve different functions. For example, you can design a plan using Photoshop. The teaching characteristic of current advertisement major is to ask student union to use computer software to finish advertisement design. Students should be proficient in the use of relevant software and design skills. Advertisement design needs to make all kinds of poster, display board, flyer, etc. Students should master the skills of designing software application and be creative in designing. But at present the advertisement profession USES the teaching material existence certain flaw. There is a lack of creative content in the textbook. In the process of practical training, we did not combine the characteristics of advertising majors. Therefore, although students have mastered the use method of design software, in the implementation of advertising design, the work lacks innovation and lacks innovation. The teaching effect has certain limitation.

\subsection{The poor effect of practical training}

Advertising design majors are closely related to practice. However, the practical teaching in some schools mainly adopts the way of teacher demonstration. Student learning is a holistic model. Although the teachers also provide guidance, the students' learning style is difficult to improve their creativity. The defect of teaching mode is simple imitation, single content, difficult to improve students' enthusiasm for innovation. Students have no interest in innovation, so it affects the teaching effect of practical training. In addition, students' learning ability is somewhat different, and 
the limitations of this teaching mode are reflected in the difficulty in meeting the differentiated needs of students at different levels. Students' learning effect will be affected. This is not conducive to improving students' innovative thinking and practical ability.

\section{Improvement Measures of Advertising Design Teaching}

The teaching of advertisement design should pay attention to the cultivation of students' ability and take the training of technical application talents as the teaching goal. Teaching should adopt a reasonable teaching method and pay attention to improving students' practical ability. Teaching methods should pay attention to flexibility and diversity. Teaching reform should be conducive to improving teaching results. In order to ensure that students have comprehensive ability, the teaching design will integrate theory and practice separately, forming a teaching mode with professional characteristics. The teaching method can fully reflect the system and pertinence. The teaching reform should combine with the characteristics of advertising major and analyze the current social demand standards for advertising talents. We should combine the characteristics of advertising major to determine the quality of students, and then design the reform of teaching methods. Only in this way can we construct a teaching model suitable for the new media era. Advertising teaching should realize the interaction of talent demand, teaching process and students' ability improvement. The orientation of teaching is to improve students' practical ability. This is conducive to the cultivation of high quality applied talents. The rationality of method should be paid attention to in teaching reform. The teaching method should be improved continuously in the teaching practice to ensure scientific and reasonable. In the implementation of teaching, relevant teaching contents should be re-organized according to functions and features. The new teaching mode should be combined with the requirement of improving students' comprehensive quality. The course should be integrated with the teaching requirements of the new media era. We should choose the content according to the teaching objective. These contents should be combined with the characteristics of students and majors. In this way, we can achieve the optimal teaching effect through objective analysis.

\section{Main Measures of Advertising Design Teaching Reform}

\subsection{Reasonable division of teaching contents}

Advertisement design specialty has certain particularity. We can divide the teaching content of advertising design into different modules, which are theoretical module, case analysis module and design practice module. The teaching of the theoretical module mainly includes the basic theory of advertisement design, color application, composition principle and the use method of all kinds of design software, such as common advertising design software Photoshop, the use skill of CorelDRAW. This module is the foundation of other teaching. The teaching content of the case analysis module is to explain some classic advertisements. The method of case analysis is used to help students understand the design method, creation method and presentation skills of the designer. Students can master necessary creative thinking through study. The main content of the design module cultivates students' advertising design ability and helps them form innovative design thinking.

\subsection{Main measures of teaching reform}

\subsubsection{Advertising design theory teaching}

The teaching of advertising design theory mainly involves the relevant theories of advertising design. Students can master the basic methods of advertising design through relevant theoretical study. They can also learn about the features, key design points, design elements, design ideas, and the presentation and production process of advertising. On the basis of advertising design, we should let students learn some mainstream design software. Students learn how to use the software in a custom state. They have the basic ability to use, and combine the use of software to explain the 
application methods and skills of various colors in advertising design, advertising composition methods, text editing and other relevant content.

\subsubsection{Teaching in case study}

Advertising has developed over the years into many classic cases. In teaching, we should pay attention to improving students' design level with the help of classic cases. We should combine the characteristics of new media advertising, such as network video, pictures and other actual advertising cases. These practical cases guide students to master the design principles of advertising and creative expression techniques. Students can have an in-depth understanding of the application areas and forms of advertising. For example, we can combine with online advertisements, so that students can fully understand the characteristics of advertising communication in the new media era, and expand students' design ideas with the popular classic works in the Internet.

\subsubsection{Teaching of advertising design practice}

The key of advertising design is creative design. Therefore, in the teaching of advertising design, we should pay attention to improving students' creative level. Students should consciously collect advertising materials in their life and pay attention to advertisements from various aspects. Advertising design teaching can adopt operation to let the students to complete their own according to proposition in the form of advertising design, students through a comprehensive analysis of the characteristics of the product, analysis of the potential consumers, complete with creative advertising design, in addition, can also be combined with social hot issues in the teaching of public service ads design, enhance the students' sense of social responsibility, the advertising works more ground, more original.

\section{Key Points of Advertising Design Teaching Reform}

\subsection{Combined with the actual situation as much as possible}

Instances of advertising materials due to the number of sometimes difficult to meet the requirements of teaching, so teachers in the teaching of teaching should pay attention to collect the actual cases, especially in advertising influential works, through these works, lets the student in the actual work of learning to the nutrition absorption, helps to cultivate students' innovative thinking.

\subsection{Combined with the characteristics of advertising design for teaching}

Advertising design teaching has a certain particularity, so advertising teaching should fully consider the characteristics of advertising design. Teachers' teaching should be comprehensively analyzed with the design ability of students, and various teaching methods can be adopted in teaching, especially in the current new media era, so that students can master the methods of advertising design under the conditions of new media, so as to achieve the teaching objectives of advertising design. In the teaching process of advertising design, teachers should fully inspire students' design inspiration, constantly provide students' design ability, and enhance the appeal and visual impact of design.

\subsection{Focus on improving students' creative level}

In the teaching of advertising design, teachers should pay special attention to improving students' creative level. Advertising design reflects the creative level of designers, and the expression of advertising works is related to the creativity of designers. For example, in order to increase the attention of the audience, the advertisement design will use the expression of strong color contrast, and the application of color will break through the original color matching rules to achieve the effect of deepening the theme.

\section{Conclusion}

The development of new media brings new challenges to traditional advertising design teaching. 
Advertising design teaching should break through the original teaching mode and carry on the corresponding reform and innovation to the teaching. Only in this way can the overall effect of advertising design teaching be improved. In the new media era, advertising design teaching should combine the characteristics of advertising communication in the new media era, the characteristics of students and the characteristics of advertising design, and adopt various measures to improve the teaching effect of advertising design.

\section{References}

[1] Li Minghui. Analysis on the necessity of advertising design teaching reform in the new media era [J]. China master dissertation full-text database, economics and management album, 2016 (10).

[2] Liang Yulin. How to carry out advertising design teaching reform in the new media era [J]. Culture education, 2014 (10).

[3] Ding Yupei, li ling. Discussion on advertising design teaching reform in new media environment [J]. Journal of Chifeng college: natural science edition, 2015 (9).

[4] Zhang Jiang, Zhang Chunyu. Practice of advertising academic teaching reform in the context of new media -- taking graphic design as an example [J]. Communication and copyright, 2017 (2).

[5] Li Yubin. Experience and inspiration of financial media times advertising undergraduate education -- a case study of Austin, university of Texas, USA [J]. Friends of editors, 2016 (3).

[6] Wang Ying. Teaching reform ideas of advertising design in the new media era [J]. Journalism, 2014 (6).

[7] Xu Jiannan. Innovation of theory and practice teaching of advertising design course [J]. Hua Zhang, 2015 (10).

[8] Wang Zi. Discussion on the teaching reform of advertising design major in new media era university [J]. Research of art education, 2017 (3). 